\title{
COMPUTATIONAL MODELLING OF BELT OF TIRE-CASING
}

\author{
Jan Krmela ${ }^{1}$, Vladimira Krmelova ${ }^{2}$ \\ ${ }^{1}$ University of Pardubice, Czech Republic; ${ }^{2}$ Alexander Dubcek University of Trencin, Slovakia \\ jan2.krmela@post.cz,jan.krmela@upce.cz
}

\begin{abstract}
The paper is focused on computational modelling of composites with elastomeric matrix and steel or textile cords, such as belts of tire casings for passenger cars. The main attention is paid to creation of computational models of the steel-cord belt and textile carcass. The sidewall of a tire casing shows the material of cords and number of plies in the sidewall and under the tread of the tire casing. Normally, the sidewall consists of one or two polyester plies and in the tread there are, e.g. four plies: one polyester ply, two steel-cord plies and one polyamide ply. The Finite Element Method using the program system ANSYS is applied to the computational modelling. In relation to the computational modelling of stress-strain analyses for belts of tire casing, it is necessary to pay attention to the materials as well as the geometric input data aspect in order to make precise output results. The SOLID186 element type and Mooney-Rivlin material parameters for elastomer are used. The geometric parameters are obtained by an image analysis of the cross-section of the tire casing. For validation, the experimental data from tensile and bend tests are used. The results from computational modelling provide better understanding of the mechanical properties of composites with steel or textile reinforcements. The obtained outputs of computational modelling of belts can be used for geometry and cordsituate optimization (angle of reinforcement). The purpose of the optimization is to obtain characteristics (stiffness parameters in individual directions) of belts for predicting deformation behaviour of a tire.
\end{abstract}

Keywords: tire casing, elastomer, Mooney-Rivlin, FEM, ANSYS.

\section{Introduction}

Tires are essential elements used in the interactions between vehicles and roads, which secure the transmission of force with the ability to mitigate the inequality of roads [1]. From the aspect of new-generation tires, the low rolling resistance is expected, because it is one of the overall requirements for modern cars, the tires of which are in the interaction with the road. Therefore, there are expected excellent material and other parameters of casings in order to well secure the right functioning and a long service life of a tire with respect to the working requirements of an automobile. From the perspective of material composition, construction as well as geometry, there is a continuous development of the radial tires [2] because of the increasing requirements as well as higher construction speeds of passenger cars. The mentioned development is mostly based on advanced methods including computational modelling.

The computational modelling of tires by the Finite Element Method allows solving of various ways of loading. It is possible to deal with static tire models, if only static load should be applied (car stands, the target is to determine deformation conditions of inflated tires loaded by the vertical force) or dynamic tire models, which will represent real states of tires, such as the tire impact on the specific barrier at a certain car speed.

It is necessary to have knowledge about the geometry, material parameters, cross-section and structure of a tire-casing - construction-reinforcing plies (number of layers of a belt and carcass, information about a bead and cap ply) and other parameters for creation of computational models of tires. The sidewall also shows the material of cords and number of plies in the sidewall and under the tread. The sidewall of a tire for passenger cars consists of one polyester ply and in the tread there are four plies: one polyester-, two steel- and one polyamide ply. A tire with the symbol Extra load may have two polyester- or two polyamide plies.

It is important to experimentally determine the material parameters used for the description of each individual part of tire-casings [3;4]. E.g. the material parameters, as the modulus of elasticity and Poisson ratio describe the textile fibre. For the description of elastomer parts (rubber) of tire-casings there are used several material models of the viscoelastic behaviour of the material - constitutive models, the Mooney-Rivlin (MR) model is the most commonly used. The MR model is the most commonly used for computational modeling of tires and the model can be well applied for the range of elongation up to $150 \%$. 


\section{Materials and methods}

The paper [5] describes the geometric parameters of single-layer specimens of tire casings with different cord-angles $\left(0,25,45,60\right.$ and $\left.90^{\circ}\right)$ for tensile tests. In this paper, the geometric parameters of rectangle shape specimens of the belt of tire-casing, which will be used for computational modeling, are: a length of $195 \mathrm{~mm}$, a width of $35 \mathrm{~mm}$, initial length between clamps of a test machine $100 \mathrm{~mm}$ and a thickness of the specimen of $1.05 \mathrm{~mm}$. The cord diameter is $0.5 \mathrm{~mm}$. The number of cords per one meter of width is $870 \mathrm{~m}^{-1}$. Polyamide 66 is used as textile reinforcement and elastomer for production of the radial tire carcass is used as matrix. The static tensile modulus of elasticity of polyamide 66 is from 900 to $3400 \mathrm{MPa}$ [2]. The test machine Autograph AG-X plus 5kN Schimadzu with a video-extensometer for large strain as tensile tests of composite materials with elastomer and viscoelastic materials with the test mode Control of software Trapenzium $\mathrm{X}$ version 1.4.5 is used for the tests of composites. The speed of loading of uniaxial static tensile tests of composites with steel cords is $10 \mathrm{~mm}$ per min and with textile cords $250 \mathrm{~mm}$ per min, the standard temperature $20 \pm 2{ }^{\circ} \mathrm{C}$ is used. The Finite Element Method using the program system ANSYS is applied to the computational modelling.

\section{Determination of Mooney-Rivlin parameters}

To determine the Mooney-Rivlin parameters, it is necessary to carry out the tensile test for elastomer samples by the standard ISO 37 [6]. Next way, MR parameters can be determined on the basis of the Shore A hardness. The procedure is such that the Shore A hardness (it is expressed as $A$ [HSA] in equations) is converted to the elastic modulus $E$ [MPa] or shear modulus $G$ [MPa] and then the MR parameters are determined from the modulus. Following equations can be used in conversion of the mentioned hardness. These equations can lead to different results of moduli for the same Shore A hardness.

- Gent equation [7]:

$$
E=\frac{0.0981(56+7.62336 A)}{0.137505(254-2.54 A)}
$$

- equation [8]:

$$
E=\exp (0.0235 A-0.6403)
$$

- equation [9], but the elastic modulus is expressed in [psi]:

$$
E=11.427 A-0.4445 A^{2}+0.0071 A^{3} ;
$$

- Batterman/Köhler equation [10] is based on expression of dependence between shear modulus and Shore A hardness:

$$
G=0.086 \cdot 1.045^{A} .
$$

The Mooney-Rivlin parameters such as $C_{10}$ and $C_{01}[\mathrm{MPa}]$ are calculated according to:

$$
G=2\left(C_{10}+C_{01}\right) \text {, }
$$

where $C_{01}=($ from 0.2 to 0.25$) \cdot C_{10}$.

The parameter of incompressibility $d\left[\mathrm{MPa}^{-1}\right]$ can be calculated as:

$$
d=\frac{2(1-2 v)}{C_{10}(5 v-2)+C_{01}(11 v-5)},
$$

where $v$ - the Poisson's ratio, which has values close to 0.5 for incompressible elastomers and it is commonly considered to be 0.4995 for better convergence of calculations.

The resulting MR parameters have to be verified, because this is the only one possible way to find the most suitable equation (from equations 1-4) for the given application. The mentioned fact is the reason for creation of the FEM computational model (Figure 1 left) of interaction between the indenter of Shore A durometer and elastomeric samples. The problem is modelled as planar stress (with type of 
element PLANE 182) because the students version of ANSYS Workbench is used. Therefore, the thickness of the sample could not be considered in the calculation. The common construction steel is specified to be the material for the indenter, the elastic modulus is $200000 \mathrm{MPa}$ and the Poisson's ratio is 0.3. Non-linear contact is used between the indenter and tested elastomeric sample.
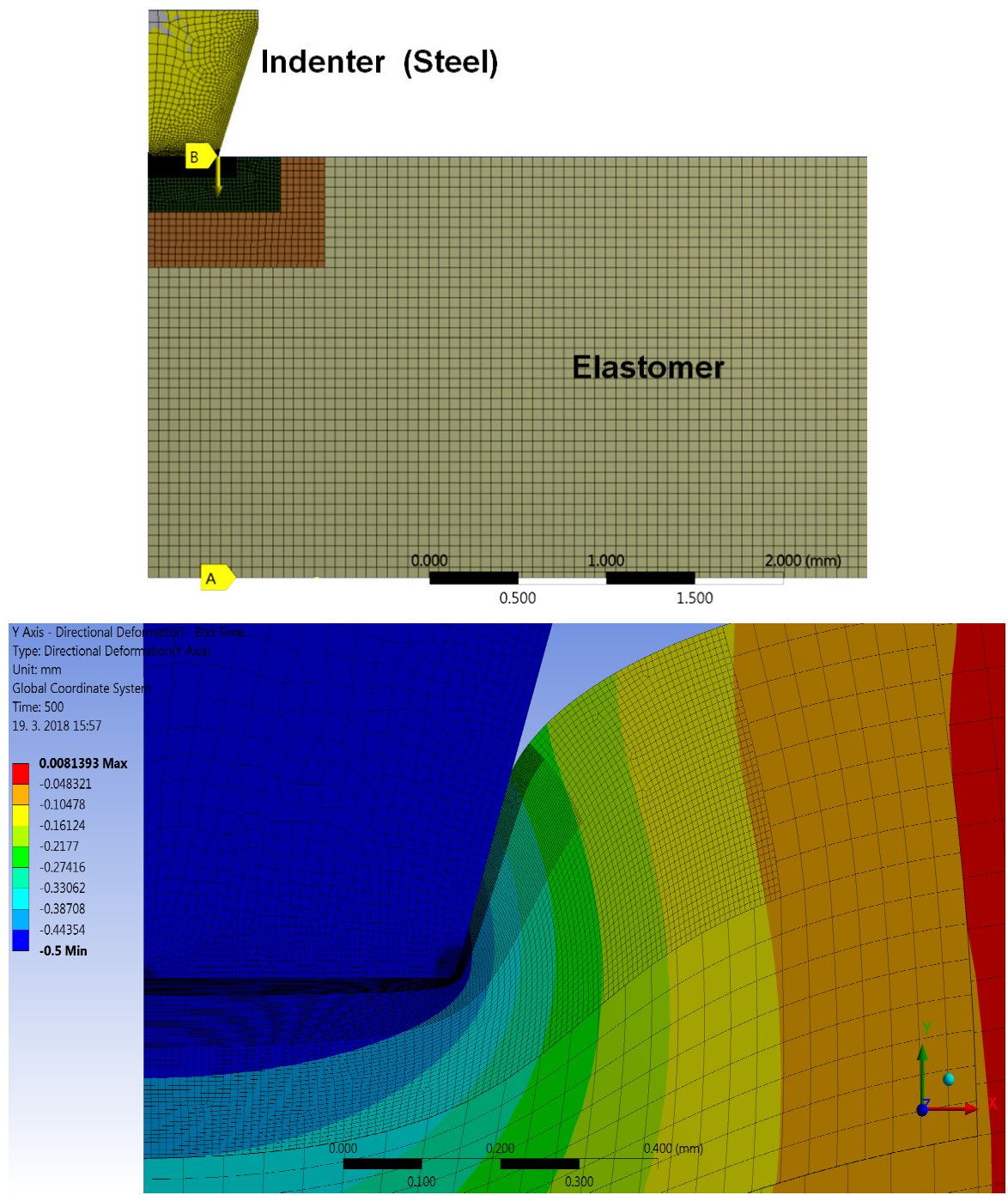

Fig. 1. Computational model for verification of calculated MR parameters (left) and strain of tested sample after indenter displacement by $0.5 \mathrm{~mm}$ (right) [11]

The given model in the program ANSYS is used for simulation of the hardness testing process by the Shore A method and the example of the strain of the tested elastomeric sample is in Figure 2 right. The MR parameters $C_{10}=1.559$ and $C_{01}=0.312$ were calculated by equation with (1) for Shore A hardness of 80 [HSA].

\section{Computational model of belt of tire-casing}

The MR parameters of elastomeric drift for the steel-cord belt [4] are $C_{10}=0.638 \mathrm{MPa}$, $C_{01}=0.284 \mathrm{MPa}$ and the parameter of incompressibility $d=0.151 \mathrm{MPa}^{-1}$. The SOLID186 element type is used. For the steel cord, the module of elasticity $E=190000 \mathrm{MPa}$ and Poisson's ratio $v=0.3$ are used, construction of steel-cord is $2 \times 0.30 \mathrm{~mm} \mathrm{[2;3],} \mathrm{the} \mathrm{cord} \mathrm{angle} \mathrm{is} 30^{\circ}$. For textile cord polyamide 6.6 with the diameter $0.5 \mathrm{~mm}$, the module of elasticity $E=3400 \mathrm{MPa}$ and Poisson's ratio $v=0.4$ are used.

The computational model (Figure 2) has a length of $120 \mathrm{~mm}$ and the initial length between the clamps of the test machine $100 \mathrm{~mm}$ is defined by boundary conditions (by removing of degrees of freedom in two axes and applying displacements on the selected nodes in areas of clamps). The model 
is reverse loaded, the displacement in the $z$-axis is defined and the reaction force at the area of a sliding clamp of the test machine is searched. It is better for quick convergence and speed solution. The PCG solver is used. The increment of every substep is $0.2 \mathrm{~mm}$ in the $z$-axis.
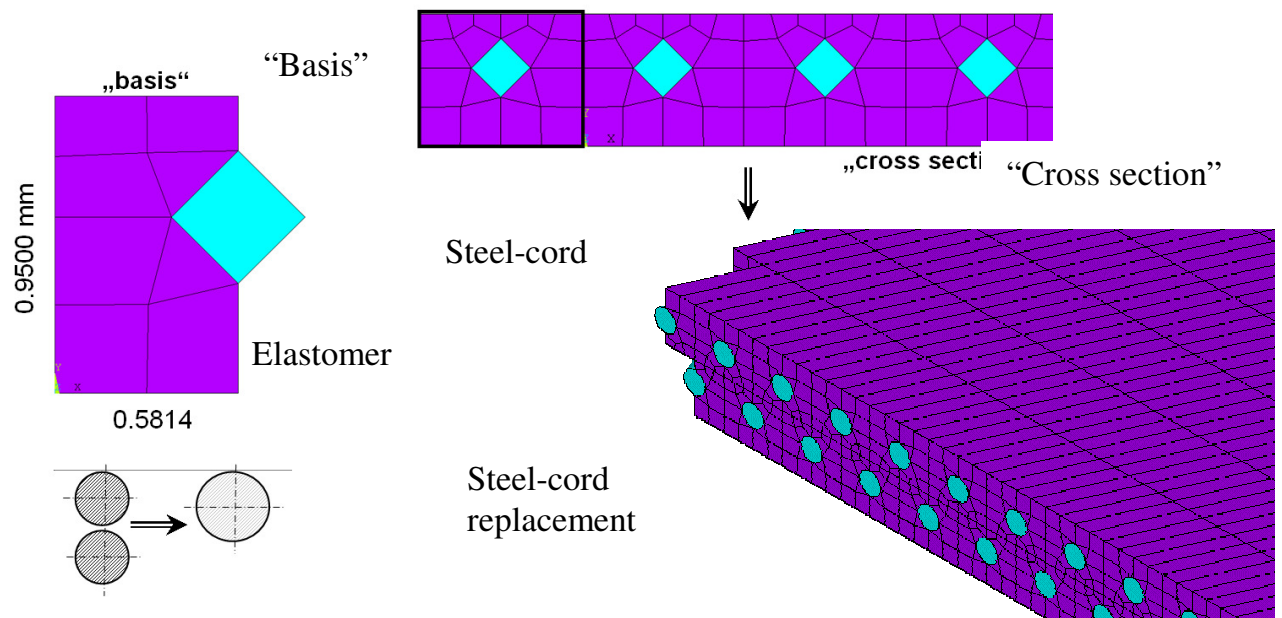

Fig. 2. Computational model of layer of steel-cord belt [3]

On the longitudinal edges of the model there is characteristic "dentation", because the computational model is designed by APDL (ANSYS Graphical User Interface) procedures for automatic creation of models from geometric parameters, such as a cord diameter, cord distance and thickness of layer. Therefore, the computational model is actual for solving of different input geometric parameters via quick computational simulations.

\section{Results and discussion}

From computational modeling of interaction between the indenter of Shore A durometer and elastomeric samples, the calculation value of hardness is 77 [HSA]. The differences between the experiment and computation are $3.8 \%$. Therefore, the created computational model of the durometer has experimental justification and the created model can be used for simulation of the hardness testing process by the Shore A method for quickly obtained results for concrete Mooney-Rivlin parameters. For specific elastomer [11] the Gent equation for calculation of MR parameters is the most appropriate. The same procedure can be applied to different elastomer parts of tire-casings [3].

The results from computational modelling of one layer of specific composite parts of a tire casing with textile-cord (polyamide 6.6 with diameter $0.5 \mathrm{~mm}$ ) as textile carcass and width of $35 \mathrm{~mm}$ are in Figures 3 and 4 as length displacement ( $z$-axis) and width displacement ( $x$-axis) for elongation of $5 \mathrm{~mm}$.

The values of reaction forces are $14.8 \mathrm{~N}$ for elongation of $5 \mathrm{~mm}$ and $28.5 \mathrm{~N}$ for elongation of $10 \mathrm{~mm}$. From the experimental data of the experiments, which were realized at work [3], the tensile force $16.3 \mathrm{~N}$ causes the deformation of $5 \mathrm{~mm}$ and the force $27.4 \mathrm{~N}$ causes the deformation of $10 \mathrm{~mm}$. The computational model has tensile stiffness and the forces very similar. It comes to this, that the force value difference between the experiment and computation for $5 \mathrm{~mm}$ deformation is $9.2 \%$.

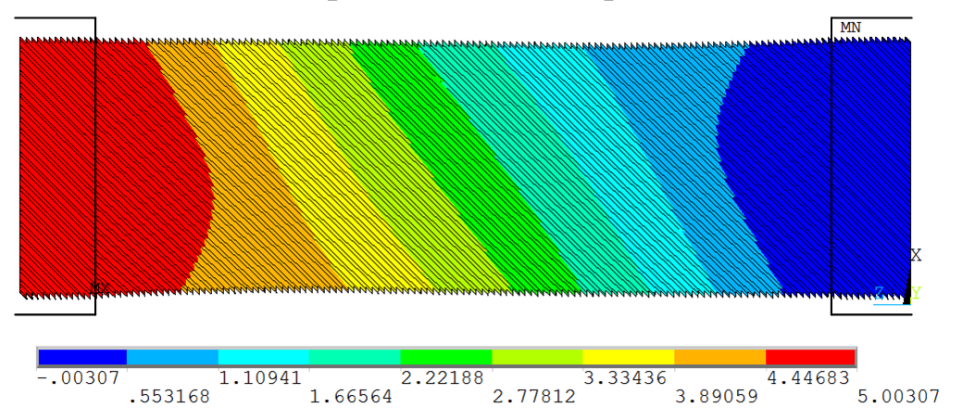

Fig. 3. Displacement filed in $z$-axis (length) for elongation 5 mm 


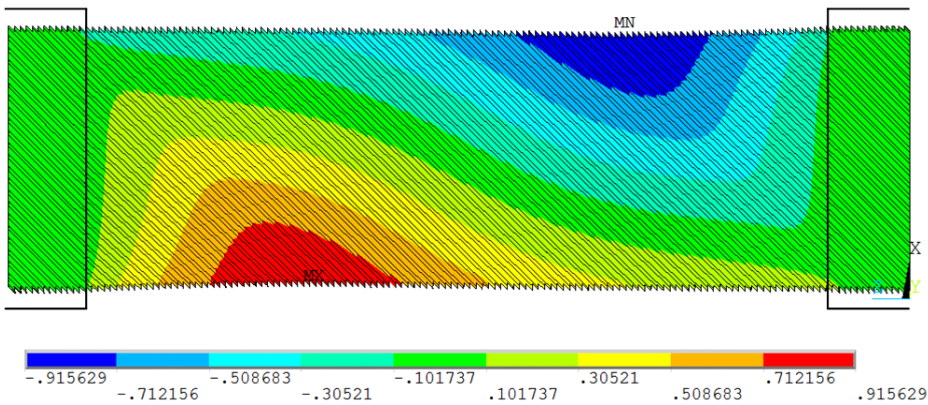

Fig. 4. Displacement filed in $\boldsymbol{x}$-axis (width) for elongation $5 \mathbf{~ m m}$

The result from the simulation of the tensile test of the two-layers of the steel-cord belt with the longitudinal orientation of the cord is shown in Figure 5. Figure 6 represents the force-deformation dependences between the test and computation of the steel-cord belt with a cord angle of $30^{\circ}$ and a width of $10 \mathrm{~mm}$ as sample verification analyses. The deformation was the measurement in the work area with initial $20 \mathrm{~mm}$ in the centre of the specimen and between the clamps of the test machine. The force value difference between the experiment and computation for $10 \mathrm{~mm}$ deformation is $13.3 \%$.

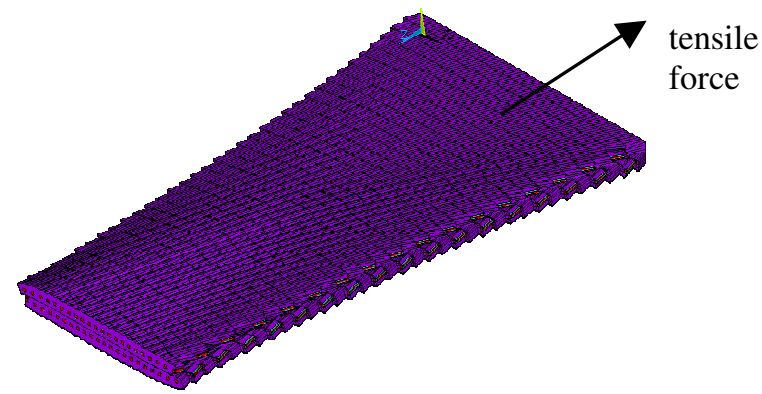

Fig. 5. Deformation of two steel-belts after tensile loading (half of symmetrical belt model)

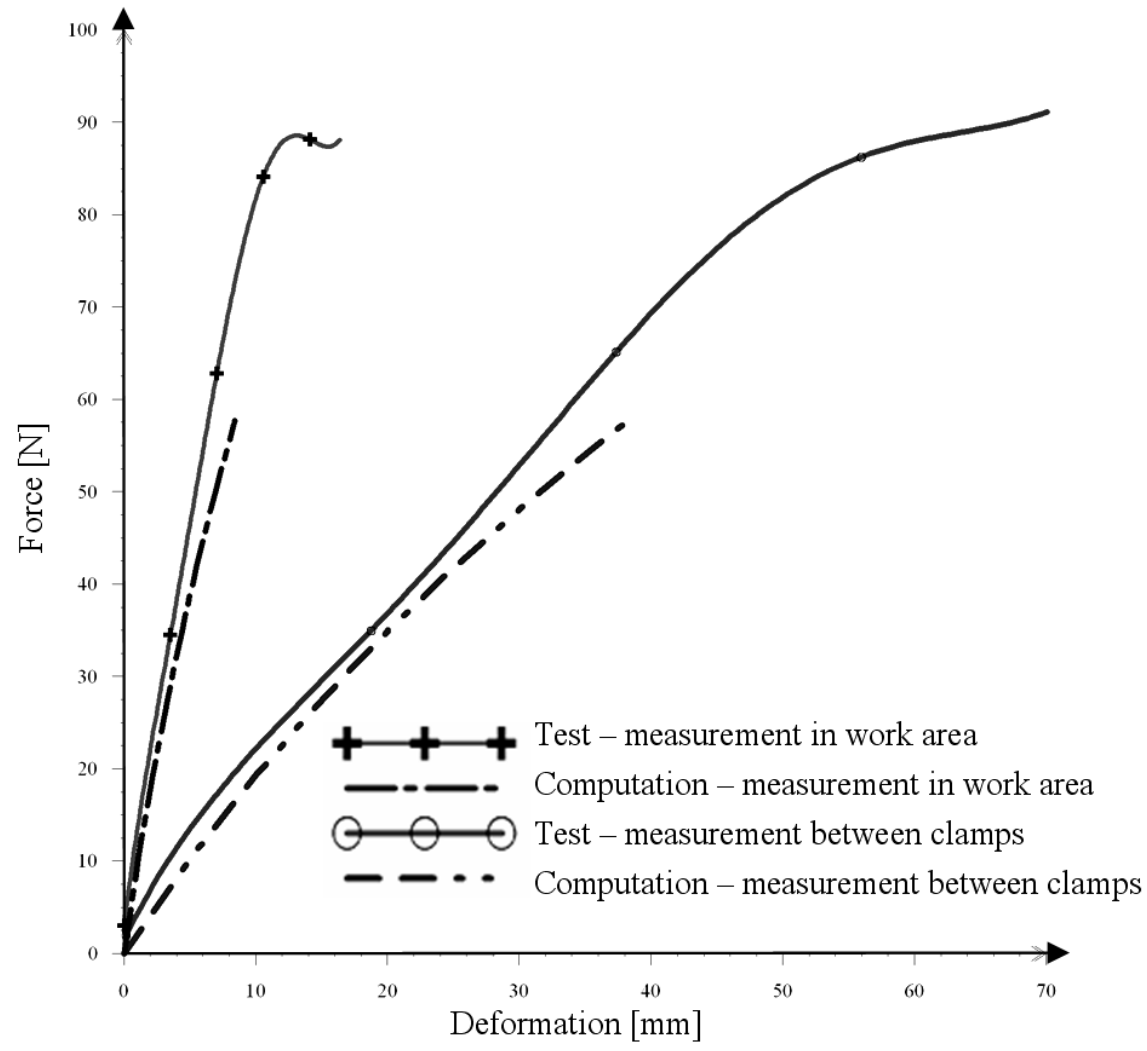

Fig. 6. Comparison between results from computational simulation and test data for sample with steel-cord angle of $30^{\circ}$ 


\section{Conclusions}

1. The moduli of elasticity of composite structures of tire-casings, such as the steel-cord belt, are needed as material input to tire computation models, too. The moduli are determined on the basis of the statical tensile and bend tests and they can be used for verification analyses between tests and computational modelling of structure parts of tire-casings. Also specific low-cyclic tensile tests of the tire textile carcass are important for obtaining material parameters.

2. Based on the obtained results, it can be concluded that we recommend to use Gent equation for calculation of the Mooney-Rivlin parameters for Shore A hardness of 80.

3. Relating to the description of a steel-cord belt for a tire casing, a special type of element is recommended to use in ANSYS and this new special type of element is, e.g. Reinf265, which is assigned to the areas of a steel-cord belt with the Solid186 type of element.

4. For future work, the methodology for the cyclic loading of elastomeric samples as well as composites at different temperatures will be proposed. A temperature chamber will be used, which is capable of testing from -70 to $180^{\circ} \mathrm{C}$. The simulation of the real load, namely, for textile-cord belts on the basis of their application in tire-casings at different temperatures.

5. The obtained outputs of computational modelling of belts can be used for the geometry and cordsituate optimization (angle of steel and textile reinforcement). The purpose of the optimization is to obtain characteristics as stiffness parameters in individual directions of belts for predicting deformation behaviour of tires.

\section{Acknowledgement}

The contribution was supported by the Cultural and Educational Grant Agency of the Slovak Republic, project No. KEGA 002TnUAD-4/2019.

\section{References}

[1] Jilek P., Šefč́́k I., Dušák L. Tires for agriculture machinery. Perner’́s Contacts. 2016, 11, pp. 8089. ISSN 1801-674X. (In Czech).

[2] The Pneumatic Tire. Gent, A. N., Walter, J. D. (Eds.). NHTSA. 2006, US DOT HS 810561.

[3] Krmela J. Tire Casings and their Material Characteristics for Computational Modeling. Scientific monograph. Czestochowa, Poland: Oficyna Wydawnicza Stowarzyszenia Menadżerów Jakości i Produkcji (Printing House the Managers of Quality and Production Association), 2017. ISBN 978-83-63978-62-4.

[4] Krmela J., Krmelová V. Tire Casings and Their Material Characteristics for Computational Modeling of Tires. Engineering for Rural Development : 16th International Scientific Conference, Jelgava: Latvia University of Agriculture, Latvia. 2017, pp. 230-235.

[5] Shiguo R. et al. Mechanical Properties and Failure Behaviour of Cord/Rubber Composites. Applied Composite Materials. 2004, 11(6), pp. 353-357.

[6] ISO 37: Rubber, vulcanized or thermoplastic - Determination of tensile stress-strain properties.

[7] Hyperelastic coefficient convertion. 2011. [online][16.02.2019] Available at: https://polymerfem.com/forum/ polymerfem-downloads/general-hyperelastic-models/1237-linearelastic-hyperelastic-coefficient-conversion.

[8] Reuss B. Convert Durometer to Young's Modulus. 2011. [online][16.02.2019] Available at: https://www.cati.com/ blog/2011/07/convert-durometer-to-youngs-modulus/.

[9] Mooney Rivlin Constants. 2005. [online][16.02.2019] Available at: http://xansys.org/forum/viewtopic.php?p = $51617 \&$ sid = 609a8612c34eb2eec373756fd062aea2.

[10] Constitutive Models for Rubber. Dorfmann, A., Muhr, A. (eds.). 1999. Rotterdam, Netherlands. ISBN 90-5809-113-9.

[11] Kvasnica T. Examination of Designed Structure Used for Weightlifting in CrossFit by FEM (In Slovak). 2018. Diploma thesis, Faculty of Industrial Technologies, Alexander Dubček University of Trenčín, Púchov, Slovak Republic. 